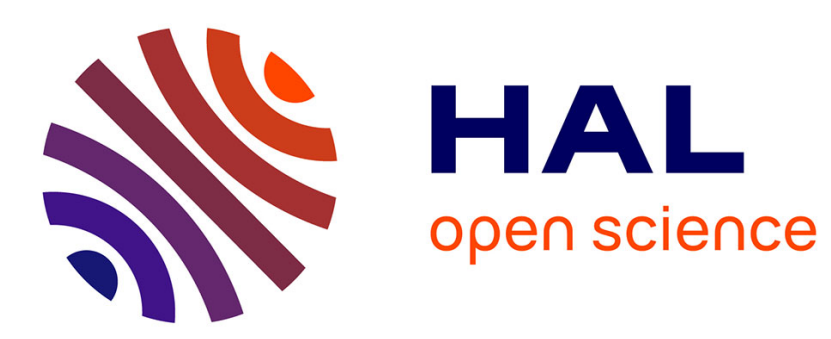

\title{
Implementing Total Lifecycle Product Sustainability Through True Lean Thinking
}

\author{
M. A. Maginnis, B. M. Hapuwatte, I. S. Jawahir
}

\section{To cite this version:}

M. A. Maginnis, B. M. Hapuwatte, I. S. Jawahir. Implementing Total Lifecycle Product Sustainability Through True Lean Thinking. 14th IFIP International Conference on Product Lifecycle Management (PLM), Jul 2017, Seville, Spain. pp.544-553, 10.1007/978-3-319-72905-3_48 . hal-01764156

\section{HAL Id: hal-01764156 \\ https://hal.inria.fr/hal-01764156}

Submitted on 11 Apr 2018

HAL is a multi-disciplinary open access archive for the deposit and dissemination of scientific research documents, whether they are published or not. The documents may come from teaching and research institutions in France or abroad, or from public or private research centers.
L'archive ouverte pluridisciplinaire $\mathbf{H A L}$, est destinée au dépôt et à la diffusion de documents scientifiques de niveau recherche, publiés ou non, émanant des établissements d'enseignement et de recherche français ou étrangers, des laboratoires publics ou privés. 


\title{
Implementing Total Lifecycle Product Sustainability through True Lean Thinking
}

\author{
M. A. Maginnis ${ }^{1}$, B. M. Hapuwatte ${ }^{2}$, I. S. Jawahir ${ }^{2}$ \\ ${ }^{1}$ Institute of Research for Technology Development (IR4TD), Lean System Program, \\ Department of Mechanical Engineering, University of Kentucky, Lexington, KY, USA \\ ${ }^{2}$ Institute for Sustainable Manufacturing (ISM), Department of Mechanical Engineering, \\ University of Kentucky, Lexington, KY, USA \\ amaginnis@uky.edu
}

\begin{abstract}
Recent expansion of the manufacturing industry's customer requirements include product lifecycle considerations covering environmental, economic and societal concerns. Awareness for the need to implement sustainable manufacturing (SM) practice continues to grow but the implementation rate appears to be relatively slow. In cases where successful SM implementation depends on the ability to compete in the marketplace in terms of quality and cost, lean manufacturing concepts have been applied to help manage the product lifecycle. Unfortunately, most lean manufacturing applications in SM focus on the use of basic lean tools such as 5S, visual management and kanbans, etc., implemented as a series of management-directed projects or Kaizen activities without full engagement of the people doing the work. Consequently, improvements made under these conditions are often short-lived and relatively limited. True Lean benchmarks the Toyota Production System (TPS) and includes often overlooked critical operational elements aimed at developing and sustaining team member engagement for continuous improvement (CI). This paper discusses important concepts of sustainable PLM and True Lean and introduces an integrated model called the 'Benevolent Production System' as a guide to continuously improve total lifecycle product sustainability.
\end{abstract}

Keywords: Benevolent Production System, Benevolent System, Lean Manufacturing, True Lean, Lean Thinking, Toyota Production System, Sustainable Manufacturing, 6R concept, Product Lifecycle Management, Life-cycle

\section{Introduction}

Industries worldwide are facing more stringent and numerous regulation on processes and systems required to produce products through all stages of their lifecycle. While some organizations may see these regulations as obstacles, they can be also viewed as an expansion of customer requirements and therefore part of the value proposition for the customer. To be successful, sustainable manufacturing must meet the triple bottomline (TBL) requirements designed to positively impact the economy, environment and society throughout a products' lifecycle. In many instances, meeting these demands

adfa, p. 1, 2011.

(C) Springer-Verlag Berlin Heidelberg 2011 
will require the use of new manufacturing processes and materials to meet TBL requirements through the use of 6R (reduce, reuse, recycle, recover, redesign and remanufacture) [1] thinking. This can add significant complexity to product lifecycle management (PLM) and would require a (new) learning environment within participating organizations to master and continuously improve methods needed to take full advantage of the new processes and materials and economically meet market demands.

Lean manufacturing or 'lean' is a term coined to describe the Toyota Production System (TPS) and is a proven method to fulfill customer expectations in terms of quality and cost, by eliminating waste throughout the system [2, 3]. Unfortunately, most organizations focus on the application of lean tools (specific IE related concepts) and as a result, the failure rate for lean implementations has been estimated at between $70 \%$ to $98 \%$ [4]. However, done correctly, the application of TPS principles and practices or True Lean, which focuses on TPS and the thinking behind it [5], can create a learning environment resulting in sustained CI over long periods as demonstrated by Toyota [6, 7].

The authors of this paper believe that the successful application of True Lean thinking within organizations engaged in the application of any of the 6Rs of sustainable manufacturing could provide a significant strategic advantage in developing and meeting new market requirements. As in the more general application of lean mentioned above, the literature shows the application of lean manufacturing as a way to improve lifecycle sustainability has primarily focused on the use of lean-related tools, centered around a single aspect (mainly environmental) of manufacturing sustainability. Thus, in this paper, while discussing the integration of lean principles within sustainable manufacturing, a new concept called the "Benevolent Production System" (BPS) is introduced to support a more effective implementation model for sustainable manufacturing practices in industry through the integration of True Lean thinking.

\section{$2 \quad$ Literature Review}

\subsection{Sustainable Manufacturing}

According to Jawahir et al. [8], sustainable manufacturing (SM) practices occurring at the product, process and systems levels must reduce their negative impact on TBL aspects, while maintaining or improving both quality and overall lifecycle cost benefits which are generally not addressed by traditional or Green Manufacturing. Shuaib et al. [9] introduced the Product Sustainability Index (ProdSI) framework, to comprehensively and quantitatively evaluate all the important sustainability-related aspects of products, and provide an index to compare their sustainability content. In recent work, Hapuwatte et al. [10] identified the importance of ProdSI, especially when alternate manufacturing methods such as additive manufacturing are available, adding to the complexity of choosing the optimum sustainable designs and processes.

Jawahir et al. [11] also identified the importance of 'total lifecycle sustainable manufacturing' to ensure all four major stages of a product's lifecycle (Pre-manufacturing, Manufacturing, Use and Post-use) are considered when evaluating SM. The literature further suggests the need for applying the $6 \mathrm{R}$ concept $[1,12]$ to successfully implement 
SM. This work also shows how each $\mathrm{R}$ can be incorporated into different stages of the lifecycle to enable a 'closed-loop material flow', which is essential to maximize the product lifecycle sustainability [11]. While there is a considerable number of recent studies related to SM, the focus on implementing total lifecycle sustainable manufacturing is somehow limited.

In a related issue, Grieves [13] developed models describing the potential application of lean tools to address PLM issues. These models illustrate the effective use of information to reduce potential inefficiencies in product design, manufacture, support and disposal. Our work conceptually extends the application of lean principles/concepts to all aspects of total lifecycle sustainability, including the 6Rs, and systemically integrates the critical component of respect for the people doing the work (team members or TMs), emphasizing human development and engagement.

\subsection{Conventional Lean Manufacturing and True Lean Thinking (TPS)}

As mentioned above, lean manufacturing [2] was originally based on the Toyota Production System (TPS) [14] which was conceived as a method to fulfill customer expectations for high quality products while eliminating waste and reducing cost within the entire manufacturing system by fully utilizing the workers' capabilities. The literature $[15,16]$ focuses on a number of individual tools available within lean, such as $5 \mathrm{~S}$, Just-in-Time (JIT), problem solving, value and waste identification, cellular manufacturing, kanban systems, Single Minute Exchange of Dies (SMED), Total Productive Maintenance (TPM), Value Stream Mapping (VSM), etc.. Literature sources [15, 17] also identify instances of implementing multiple lean concepts, emphasizing the importance of viewing lean as a philosophy rather than simply a set of individual tools [18]. However, some prior publications $[15,19]$ also identify the concept of respect for people, a core principle of TPS [20], as a primary missing component in most 'conventional' lean implementations. New [21] has compared the difference between the TPS idea of respect and dignity for people based on their ability to improve their work as opposed to the Western model of 'dignity at work' which emphasizes variety and autonomy in core activities without consideration of CI. In addition TPS also encompasses the concept of developing people by providing them with an environment to more fully utilize their capabilities as a reflection of Toyota's core principle of respect for TMs at every level [20, 21].

CI is the other core principle embodied in TPS, focusing on reducing cost while improving the product quality through waste elimination. It is a learning process focused on an ever-increasing understanding of individual processes performed using standard methods (standardized work), based on the idea of 'good method=good results'. Unlike conventional thinking, according to TPS or True Lean (used interchangeably in this paper), the people doing the work have the greatest understanding of how to improve it. Basic misunderstandings of the thinking behind TPS has led to a huge variation in the definition of lean resulting in the need for the University of Kentucky (UK) Lean Systems Program (initiated by and still managed by Toyota Executives) to specifically define the term 'True Lean' to describe their program [5]. According to the 
UK program, True Lean is defined as: 'the group by themselves, using systematic problem solving, to improve the work they do, towards the achievement of the company's targets and goals, when and only when the company culture is the reason the improvement occurs'. According to this definition, the continuous application of systematic problem solving, based on the PDCA (Plan, Do, Check, Act) learning cycle [5, 6, 22] depends on the ability of the group to rapidly identify and eliminate abnormalities where the work is performed at every level of the organization. Incorporating successful problem solutions (countermeasures) into standardized work is the way to keep the problem from coming back, establishing a new baseline for $\mathrm{CI}$ and a strategic advantage for any organization [6].

\subsection{Lean and Sustainable Manufacturing}

Literature discussing the application of lean manufacturing or thinking in sustainable manufacturing is sparse and largely focuses only on the environmental aspect (discussion of 'Lean and Green' manufacturing). Yet, sustainability as discussed above must include all three aspects of TBL.

One case study [23] explores the implementation of the lean concept of waste elimination in SM, and states that lean transcends Green. Chiarini [24] illustrates how certain lean concepts such as VSM, 5S, cellular manufacturing, SMED and TPM can be used to improve the environmental impact of the manufacturing plants.

In some applications of Lean to Green manufacturing cited, lean is seen as a means to reduce (i.e., make the products, processes and systems 'leaner') the environmental impact of manufacturing through improved efficiency and waste reduction [25, 26]. In other studies [25, 27] its effectiveness is disputed based on insufficient evidence by citing the importance of conducting comprehensive lifecycle assessments to truly understand the total impact. However, at least some of the available literature [25, 28] agrees on the synergistic impact of implementing Lean and Green together. Rothenberg et al. [26] go so far as to conclude attention to human development factors such as training and jobs skills could enable even better identification of waste reduction opportunities.

As mentioned, creating a learning environment through the implementation of True Lean, represents an essential strategic advantage for practicing SM, not only to reduce waste and cost, but to deal with increasing complexities effecting every aspect of SM. However, the relationship between lean and SM has not been adequately studied. The concept of the Benevolent Production System introduced below is our attempt to integrate the two concepts in order to guide the development of CI capabilities in current and future sustainability activities.

\section{Discussion}

Figure 1 is based on Zhang et al. [29], and illustrates the product lifecycle stages of: Pre-manufacturing (PM), Manufacturing (M), Use (U) and Post-use (PU) shaded in purple, and their relationship to the 6 Rs along with the gateways to each $R$. The figure 


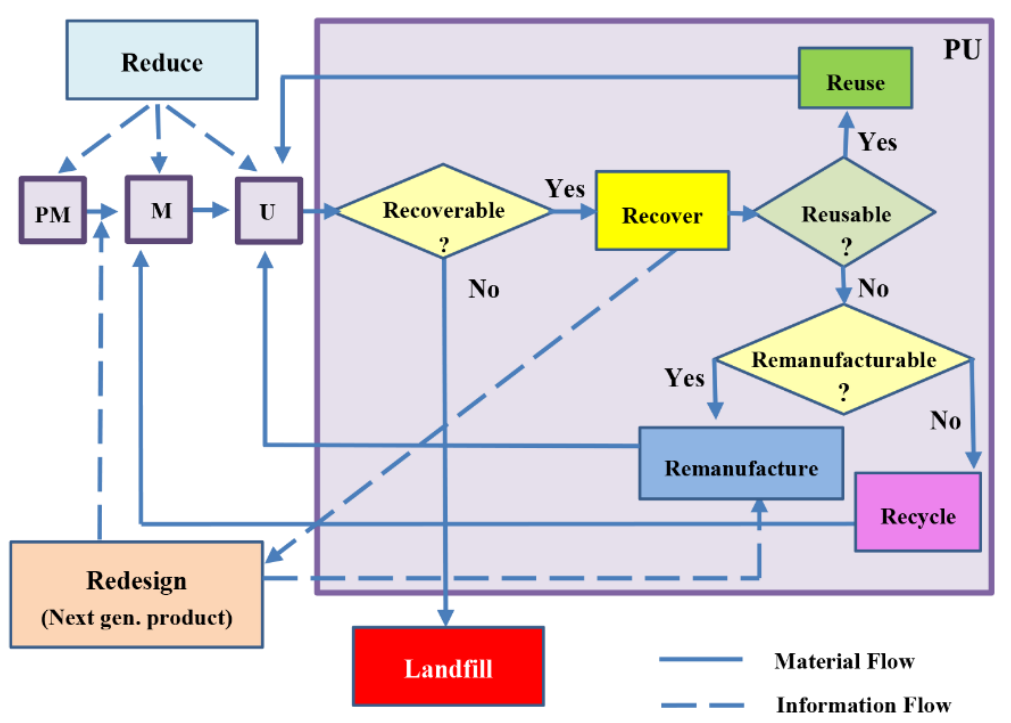

Fig. 1. 6R decision flow diagram adapted from the work of Zhang et al. [29]

has been adapted to distinguish between the material and information flows in order to reveal potential feedback loops essential for continuous learning.

The model presented in Fig. 2 illustrates the primary information feedback loop for total lifecycle product development (TLPD). This framework was developed by extending Shetty's conventional product development concept [30], which appears to neglect critical and formalized two-way communication between each stage of development. This is especially important between the "End-of-Life" and "Customer Requirements" stages because EOL concerns must be included in customer requirements to achieve total lifecycle sustainability. The occurrence of information flow between each stage of product development illustrated in Fig. 2 represents opportunities to apply true lean thinking as a way to develop continuous learning capabilities throughout a sustainable system. In sustainability, success is typically defined by the ability to meet the requirements of the TBL and are usually centered on the needs of the customer and the company. True Lean extends the definition of success to encompass the needs of the people engaged in creating the product (TMs), which, based on the success of TPS, can be expected to increase the ability of the system to meet the TBL requirements. It is the successful integration of the technical and human elements of the production system which results in what we call a 'benevolent production system'.

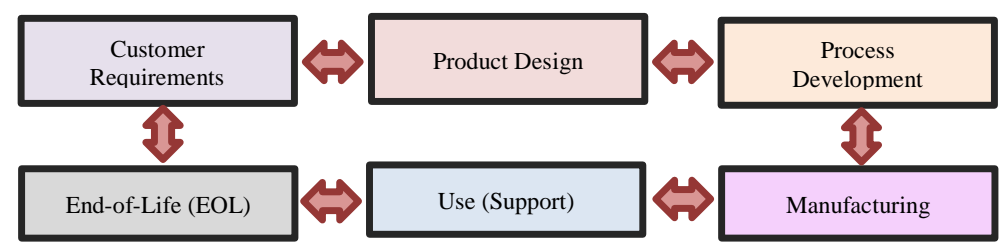

Fig. 2. Primary feedback loop for total lifecycle product development (TLPD) 


\subsection{Definition of Benevolent Production System}

As mentioned above, regulatory and other forces have resulted in the expansion of customer requirements to include improved sustainability content in manufactured products. As the section on lean manufacturing suggests (sec. 2.2), a True Lean manufacturing system represents one of the most effective ways to manage product lifecycle issues for achieving safety, quality, cost, productivity and human resource development objectives to meet the increasingly complex customer demands upon sustainably manufactured products.

The "Benevolent Production System" (BPS) model illustrated in Fig. 3 is defined as the successful integration of the operational elements of TPS or a True Lean system with the primary elements of TLPD to create a CI operation based on 6R thinking. This system, like TPS, is centered on the core principles of CI and Respect for People [20]. The BPS model was developed using gap analysis based on the UK True Lean Operating Environment model [5] and general observations of sustainable manufacturing activities (6Rs \& TLPD). Its purpose is to help provide a more focused pathway for developing CI capabilities within SM organizations.

The system is referred to as 'Benevolent' because it incorporates three basic criteria including: (1) the primary precepts of sustainability throughout the lifecycle, which strive to fully utilize existing resources with minimal impact on TBL; (2) it supports the highest customer satisfaction by promoting the production of quality products at lowest cost and on-time delivery; while (3) respecting society and the people who do the work. A benevolent production system therefore provides a win-win-win for the environment, economy and society (TBL).

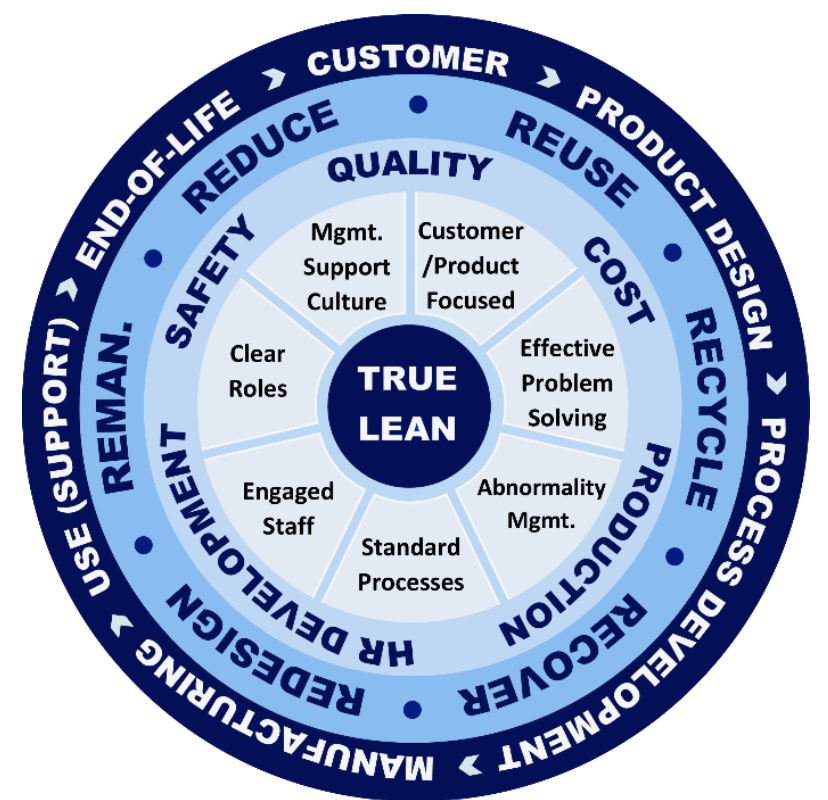

Fig. 3. Benevolent Production System model representing the integration between True Lean and Sustainable Manufacturing 


\subsection{Major TPS (True Lean) Operational Elements of BPS}

The Benevolent Production System Model in Fig. 3 includes the core True Lean operational elements required to sustain CI [5]. We believe these elements are particularly compatible and important for the efficient implementation of sustainable manufacturing through the lifecycle of a product. Each of these element's importance and an example of how they relate in the SM environment is described below:

Customer/Product Focused: This is the focal point of the organization since only by providing products or services which meet customer needs in terms of cost, quality and deliverability will companies survive, especially in a global market. Here the knowledge management capabilities of PLM meet the operational elements of the BPS model to help ensure appropriate sustainable process pathways (6Rs) and products are identified and developed.

Systematic Problem-Solving (P/S): An effective systematic problem solving methodology must be in place throughout the organization (One System, One Voice) to protect the customer from receiving defective products or late deliveries. Each step of product lifecycle management requires effective problem solving that enables TMs to accurately identify a problem, find the root cause, develop effective countermeasures, implement and validate them, and finally (and most importantly) incorporated effective countermeasures into the TMs standard work to keep the problem from returning. This is an especially important activity during the product design stage where most of the decisions which impact the overall lifecycle sustainability are made.

Abnormality Management: To achieve effective systematic P/S you must be able to identify problems when they occur. This is done using the concept of 'built-in-quality' to create a system capable of identifying and eliminating defects as they occur. This helps distinguish between quick fixes, chronic problems and opportunities for improvement. SM strives for maximum resource utilization, therefore both problem conditions and improvement opportunities must be readily identifiable to continuously improve towards this goal.

Standard Processes: Identifying defects and waste (problems) means workers must clearly see the difference between normal and abnormal conditions which can only occur with standard processes in place. The more quickly a problem is identified the more likely the root cause can be determined and the problem eliminated. The current standard defines the baseline for improvement and supports the ability of TMs to perform normal, value added work and identify abnormalities and waste (problems) quickly. Maintaining and developing standard work also ensures problems are eliminated without reoccurrence. In implementing SM, standardization is essential to understand how design decisions impact the sustainability content of the product.

Engaged Staff: To perform standard processes and improve upon them, TMs must identify challenges to meeting expectations and opportunities for improvement. Without their engagement, which depends on trust, developing standards and identifying abnormal conditions becomes very difficult, increasing the likelihood of passing defects to the customer and increasing costs. 
Clear Roles: Basic roles exist within the organization and at the level of production which identify who performs the normal, value added work (what the customer is willing to pay for) and who handles abnormalities, so that value added activities are not interrupted. With expanding involvement of people, SM requires efficient management of people.

Management Support Culture: Operationally, management requires visibility of the systems' status with respect to meeting customer needs. This is done through the use of Key Performance Indicator (KPI) boards to guide P/S activities at all levels of the organization. Management must also create an environment of trust between all employees so TMs feel safe and are encouraged to identify problems without fear of recrimination. The management culture supports $\mathrm{P} / \mathrm{S}$ at all levels and encourages a processfocused mentality (good process $=$ good results) by aligning HR policies to reward both method and results instead of results only or bottom line thinking. With the multi-lifecycle thinking of SM, besides the absolute necessity of having clear KPIs at all levels, and TMs involvement to meet them, there needs to be a thorough understanding of the methods used (rather than just a focus on the results) as the results must be reproducible and improved iteratively.

\section{Conclusions}

Both lean and sustainable manufacturing have been identified as two distinct concepts capable of enhancing important aspects of productivity and resource utilization. In particular, we contend the application of True Lean thinking to sustainability activities is expected to provide similar benefits as those experienced by Toyota and other 'lean' organizations. While the current literature contains studies which indicate some understanding of the application of 'lean' in sustainability, most, if not all studies appear to be limited to applying certain lean concepts or tools rather than taking a more integrated and systemic approach. Thus, one of the major objectives of this work was to explore opportunities to integrate TPS practices and principles with total sustainable product development and to understand the compatibilities and complementariness of both. Underlying philosophies of TPS, such as systematic problem solving, respect for people, CI, etc., were identified to be directly compatible with SM and 6R - a core part of implementation of total lifecycle product sustainability. As the literature review suggested, the people side of TPS is the most underrated, and even neglected, aspect in conventional lean implementations. Yet, it forms the basis for the engaged learning environment of (True) Lean, which enables the most effective use of human and other resources. The principle of Respect for Team Members in both TPS and the Benevolent Production System requires management to develop everyone in the organization and provide effective methods, training and resources so workers can be successful. This respect ultimately leads to trust, which is the cornerstone of CI. Workers must feel safe to identify problems without recrimination and to contribute their knowledge towards finding effective solutions and prevent their reoccurrence.

The approach in this initial study provides a basis for the development of a broader framework incorporating True Lean and SM. Further work will attempt to expand and 
verify the concept of a Benevolent Production System in sustainable manufacturing applications.

\section{References}

[1] K. Joshi, A. Venkatachalam, I. Jaafar, and I. Jawahir, "A new methodology for transforming 3R concept into 6R for improved sustainability: Analysis and case studies in product design and manufacturing," in Proc. IV Global Conf. on Sust. Prod. Dev. and Life Cycle Eng, 2006.

[2] J. P. Womack, D. T. Jones, and D. Roos, Machine that changed the world: Simon and Schuster, 1990.

[3] J. K. Liker, The Toyota Way: Esensi, 2004.

[4] M. R. f. Graban. (2005, 02/28/2017). Preventing Lean Failures. Available: http://leanfailures.blogspot.com/

[5] K. Kreafle, "Models to support type 3 lean implementations," in Lean Certification Program Material, ed, 2007.

[6] M. A. Maginnis, "The impact of standardization and systematic problem solving on team member learning and its implications for developing sustainable continuous improvement capabilities," Journal of Enterprise Transformation, vol. 3, pp. 187-210, 2013.

[7] J. K. Liker and M. Hoseus, "Toyota Culture," New York, McGrawHill, 2008.

[8] I. S. Jawahir, F. Badurdeen, and K. E. Rouch, "Innovation in sustainable manufacturing education," in 11th Global Conference on Sustainable Manufacturing, Berlin, Germany, 2013, pp. 9-16.

[9] M. Shuaib, D. Seevers, X. Zhang, F. Badurdeen, K. E. Rouch, and I. S. Jawahir, "Product Sustainability Index (ProdSI): A metrics-based framework to evaluate the total life cycle sustainability of manufactured products," Journal of Industrial Ecology, vol. 18, pp. 491-507, 2014.

[10] B. Hapuwatte, K. D. Seevers, F. Badurdeen, and I. S. Jawahir, "Total life cycle sustainability analysis of additively manufactured products," Procedia CIRP, vol. 48, pp. 376-381, 2016.

[11] I. Jawahir, O. Dillon, K. Rouch, K. J. Joshi, A. Venkatachalam, and I. H. Jaafar, "Total life-cycle considerations in product design for sustainability: A framework for comprehensive evaluation," in Proceedings of the 10th International Research/Expert Conference, Barcelona, Spain, 2006, pp. 1-10.

[12] I. Jaafar, A. Venkatachalam, K. Joshi, A. Ungureanu, N. De Silva, O. Dillon $\mathrm{Jr}$, et al., "Product design for sustainability: A new assessment methodology and case studies," in Environmentally Conscious Mechanical Design. vol. 5, M. Kutz, Ed., ed, 2007, pp. 25-65.

[13] M. Grieves, Product lifecycle management: Driving the next generation of lean thinking: McGraw Hill Professional, 2005.

[14] Y. Sugimori, K. Kusunoki, F. Cho, and S. Uchikawa, "Toyota production system and kanban system materialization of just-in-time and respect-for- 
human system," The International Journal of Production Research, vol. 15, pp. 553-564, 1977.

[15] S. Bhasin and P. Burcher, "Lean viewed as a philosophy," Journal of manufacturing technology management, vol. 17, pp. 56-72, 2006.

[16] R. Shah and P. T. Ward, "Lean manufacturing: context, practice bundles, and performance," Journal of operations management, vol. 21, pp. 129-149, 2003.

[17] J. P. Womack and D. T. Jones, "Lean thinking: Banish waste and create wealth in your organisation," Simon and Shuster, New York, NY, vol. 397, 1996.

[18] E. Lander and J. K. Liker, "The Toyota Production System and art: making highly customized and creative products the Toyota way," International Journal of Production Research, vol. 45, pp. 3681-3698, 2007.

[19] S. Spear and H. K. Bowen, "Decoding the DNA of the Toyota production system," Harvard business review, vol. 77, pp. 96-108, 1999.

[20] "Toyota Business Practice," (Internal training document), 2005.

[21] S. New, "Celebrating the enigma: the continuing puzzle of the Toyota Production System," International Journal of Production Research, vol. 45, pp. 3545-3554, 2007.

[22] W. E. Deming, The New Economics: For Industry, Government, Education: MIT press, 1994.

[23] G. Miller, J. Pawloski, and C. R. Standridge, "A case study of lean, sustainable manufacturing," Journal of industrial engineering and management, vol. 3, pp. 11-32, 2010.

[24] A. Chiarini, "Sustainable manufacturing-greening processes using specific Lean Production tools: an empirical observation from European motorcycle component manufacturers," Journal of Cleaner Production, vol. 85, pp. 226233, 2014.

[25] C. M. Dües, K. H. Tan, and M. Lim, "Green as the new Lean: how to use Lean practices as a catalyst to greening your supply chain," Journal of cleaner production, vol. 40, pp. 93-100, 2013.

[26] S. Rothenberg, F. K. Pil, and J. Maxwell, "Lean, Green, and the quest for superior environmental performance," Production and Operations Management, vol. 10, pp. 228-243, 2001.

[27] D. Mollenkopf, H. Stolze, W. L. Tate, and M. Ueltschy, "Green, lean, and global supply chains," International Journal of Physical Distribution \& Logistics Management, vol. 40, pp. 14-41, 2010/02/02 2010.

[28] G. G. Bergmiller and P. R. McCright, "Are Lean and Green programs synergistic?," presented at the Industrial Engineering Research Conference, 2009.

[29] X. Zhang, F. Badurdeen, K. Rouch, and I. Jawahir, "On improving the product sustainability of metallic automotive components by using the total life-cycle approach and the 6R methodology," in 11th Global Conference on Sustainable Manufacturing, Berlin, Germany, 2013.

[30] D. Shetty, "Building blocks of new product design," in Product Design For Engineers, ed: Cengage Learning, 2015, pp. 8-12. 